EISSN: 2706 -7947 ISSN: 2077- 4613

DOI: $10.36632 / \mathrm{mejas} / 2021.11 .3 .60$

Journal homepage: www.curresweb.com

Pages: 803-812

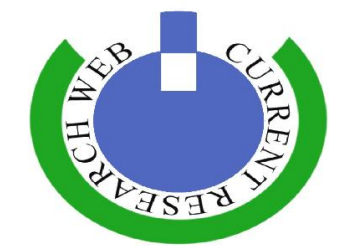

\title{
Physicochemical Analysis, Fatty Acid Composition and Heavy metals of olive oil obtained from different mills in Matrouh Governorate, Egypt
}

\author{
Sahar O. El-Shafee ${ }^{1}$, Al-Shymaa F. Ali Gheita ${ }^{2}$, Reham K. Badawy ${ }^{2}$ and Abd El-Nasser \\ G. El-Gendy ${ }^{3}$
}

${ }^{I}$ Nutrition \& Food Science Department, Faculty of Home Economics, Menoufiya University, Egypt

${ }^{2}$ Plant Ecology and Range Management Department, Desert Research Center, Egypt.

${ }^{3}$ Medicinal and Aromatic Plants Research Department, National Research Centre, 33 El Bohouth St., Dokki, Giza, 12622, Egypt

Received: 10 June 2021 Accepted: 11 July $2021 \quad$ Published: 30 Sept. 2021

\begin{abstract}
This work was conducted to determine the physical and chemical properties, Fatty Acid Composition and Heavy metals in olive oil samples which have obtained from different Mills in Matrouh Governorate - Egypt. From the obtained results, it could be noticed that there were no significant differences among olive oil mills and extraction techniques which used in these mills in view of oils values; refractive index, Specific gravity, Peroxide value and unsaponifiable matters which appeared to be approximately the same. Also, results observed that there were slight differences in free fatty acids \% and fatty acids composition between different olive oil mills. Fatty acid profiles for all olive oil samples were in the range of virgin olive oil according to IOC Standard and all mills were identical with permitted limits of extra virgin olive oil. Heavy metals $(\mathrm{mg} / \mathrm{kg})$ determined for six olive oil mills varied as follows: 1.272 - 15.44 for Al; 0.6634-17.1 for Ca; 0.8357-35.17 for Fe; 0.1592-5.043 for Mg; 0.5397-16.88 for $\mathrm{Sn}$ and 0.0031-0.1024 for Ti. On the overall, Olive oil mill No_2 showed that higher concentration from heavy metal than other mills under study. We found that the content of the heavy metals in all of the tested oils was lower than the maximum values recommended for FAO/WHO.
\end{abstract}

Keywords: Olive oil, Physical and chemical properties, fatty acid profiles, Heavy metals

\section{Introduction}

Edible vegetable oils are foodstuffs which are composed primarily of Glycerides of the fatty acids being obtained only from vegetable sources. They may contain small amounts of other lipids such as phosphatides, of unsaponifiable constituents and of free fatty acids naturally present in the fat or oil. (Alimentarius, 1999).

The olive tree, Olea europea L, valued for both its beauty and its fruit, has been a part of Mediterranean civilization since before recorded history As early as 3000 B.C. (EC, 2001).

Olive and olive oil production, which is widespread throughout the Mediterranean region, plays an important social, economic and environmental role in producing countries. Egypt occupies the 10th place in the global ranking of the countries producing less than $1 \%$ of Global production of olive oil. (IOC, 2012)

Olive oil extraction involves different processes, such as leaf removal, olive washing, grinding, beating, and separation of the oil. The amount and physicochemical properties of the produced wastes and effluents depend on the method used for the extraction. Olive oil is extracted directly from the fresh fruit of olive tree (Olea europaea L.) using only mechanical methods, in order to maintain its natural organoleptic characteristics according to the European Commission Regulation No. 1513/2001 (EC, 2001) The mechanical processes used to extract, olive oil from the olive fruit include olives crushing, malaxation of resulting paste, and separation of the oily phase by pressure or centrifugation. In the latest

Corresponding Author: Abd El-Nasser G. El-Gendy, 3 Medicinal and Aromatic Plants Research Department, National Research Centre, 33 El Bohouth St., Dokki, Giza, 12622, Egypt.

E-mail: aggundy_5@yahoo.com 
one, three different systems are commonly used: the traditional discontinuous press process, the threephase, and the two-phase decanter centrifuge methods.

According to production procedure employed and to acid content, a European directive (Anonymous 2, 2013) classifies olive oil into the following categories:

A) Extra-virgin olive oil; A natural cold-pressed oil without addition of chemicals or biochemical substances; it is characterized by acid value lower than $0.8 \%$.

B) Virgin olive oil: A natural product obtained by pressing that is not treated with chemicals; its acid value is higher than $1 \%$.

C) Olive oil: It contains a mixture of refined and virgin olive oil.

The extraction of olive oil involves different processes such as washing the olives, grinding, mixing and the extraction itself, which is the basic step of the whole process. The quantity and physiochemical properties of the waste produced will depend on the method used for the extraction (Azbar et al., 2004; Tsagaraki et al., 2004).

Heavy metals are toxic elements which can enter into the food and affects the health of people who consume the contaminated foods.

Levels of heavy metals in food and environmental samples are an important key to environmental pollution (Oreopoulou \& Russ, 2007) and their attention worldwide due to its toxic effects even at very low concentrations is given (Khaniki, 2007).

The olive oils may also be contaminated with the metals during the production process and contact with stored materials. The level of trace metals in olive oils is one of the quality parameters and also effective on oil oxidation and human health. Oxidation leading to the development of unfavorable odors and taste is one of the major reasons of deterioration of olive oils. The factors that most affect the rate of oxidation are the degree of unsaturation, the amount of oxygen, temperature, light and the presence of metals (mainly transition metals such as $\mathrm{Fe}$ and $\mathrm{Cu}$ ). (Meira et al., 2011; Sikwese \& Duodu, 2007). The trace metals enhance the rate of oxidation of edible oils by increasing the generation of free radicals from fatty acids or hydroperoxides. Benedet\&Shibamoto (2008) observed that trace amounts of $\mathrm{Fe}, \mathrm{Cr}, \mathrm{Pb}$ and $\mathrm{Cd}$ contribute oxidative effects to of lipid peroxidation

The aims of the study were Evaluation of Physicochemical properties, Fatty Acid Composition and determine the concentrations of heavy metals in olive oil samples which have obtained from different mills in in Matrouh Governorate - Egypt.

\section{Material and Methods}

The olive oil samples were obtained from six olive mills used different extraction methods in Matrouh Governorate - Egypt, the GPS Location of olive mills presented in table 1. Olive oil samples were collected during the period of $11 / 2017$. The physicochemical parameters were analyzed using official methods.

All chemicals, reagents and solvents used in this investigation were of analytical grade and obtained from Sigma agent, USA and Corneal Lab Companies in Egypt.

Table 1: GPS location of different Olive oil Mills from Matrouh Governorate - Egypt

\begin{tabular}{|c|c|c|c|}
\hline \multicolumn{4}{|c|}{ Olive oil samples } \\
\hline Mill No & GPS Location & Mill No & GPS Location \\
\hline \multirow[b]{2}{*}{ Mill_1 } & N 31 $31^{\circ} 34^{\prime} 52.44^{\prime \prime}$ & \multirow[b]{2}{*}{ Mill_4 } & N 31 $31^{\circ} 36^{\prime} 40.24^{\prime \prime}$ \\
\hline & E $027^{\circ} 20^{\prime} 00.85^{\prime \prime}$ & & E $027^{\circ} 13^{\prime} 19.46^{\prime \prime}$ \\
\hline \multirow{2}{*}{ Mill_2 } & $\mathrm{N} 31^{\circ} 35^{\prime} 33.95^{\prime \prime}$ & \multirow{2}{*}{ Mill_5 } & N $31^{\circ} 39^{\prime} 31.29^{\prime \prime}$ \\
\hline & Е $027^{\circ} 18^{\prime} 66.95^{\prime \prime}$ & & Е $027^{\circ} 04^{\prime} 28.46^{\prime \prime}$ \\
\hline \multirow{2}{*}{ Mill_3 } & N 31 $31^{\circ} 35^{\prime} 39.52^{\prime \prime}$ & \multirow{2}{*}{ Mill_6 } & N $31^{\circ} 39^{\prime} 31.29^{\prime \prime}$ \\
\hline & E $027^{\circ} 22^{\prime} 99.75^{\prime \prime}$ & & E $027^{\circ} 04^{\prime} 28.46^{\prime \prime}$ \\
\hline
\end{tabular}

\subsection{Physicochemical Analytical}

\subsubsection{Refractive index (RI)}

Refractive index was determined according to the method described by AOAC (2000) using a refract meter (NY RL-3-Poland). 


\subsubsection{Specific gravity (SG)}

Specific Gravity was determined by the standard method of A.O.A.C 17th edn, 2000. Specific Gravity at $30{ }^{\circ} \mathrm{C} / 30{ }^{\circ} \mathrm{C}=(\mathrm{A}-\mathrm{B}) /(\mathrm{C}-\mathrm{B})$

Where $\mathrm{A}=$ weight in $\mathrm{g}$ of specific gravity bottle with oil at $30{ }^{\circ} \mathrm{C}$

$\mathrm{B}=$ weight in $\mathrm{g}$ of specific gravity bottle at $30{ }^{\circ} \mathrm{C}$

$\mathrm{C}=$ weight in $\mathrm{g}$ of specific gravity bottle with water at $30^{\circ} \mathrm{C}$.

\subsubsection{Free Fatty acids (FFA \%)}

Free acidity, expressed as percent oleic acid (\% C18:1), was determined by titration of the solution of oil dissolved in ethanol/petroleum ether $(1: 1, \mathrm{v} / \mathrm{v})$ with $0.1 \mathrm{M}$ potassium hydroxide ethanolic solution. The value was evaluated according to the official methods described in the European Union Commission Regulations EEC/2568/91 and EEC/1429/92.

\subsubsection{Peroxide value (PV)}

Peroxide value, given in mill equivalents of active oxygen per kilogram of oil (meq. $\mathrm{O}_{2} \mathrm{~kg}^{-1}$ ). It gives a measure of the extent to which an oil sample has undergone primary oxidation. The value was determined as follows: a mixture of oil and chloroform/glacial acetic acid $(3: 2, \mathrm{v} / \mathrm{v})$ was left to react in darkness in a saturated potassium iodide solution; the free iodine was then titrated with a sodium thiosulfate solution. The value was evaluated according to the official methods described in the European Union Commission Regulations EEC/2568/91 and EEC/1429/92.

\subsubsection{Saponification value (SV)}

Saponification value was determined according to the AOAC (2000).

\subsubsection{Fatty acid profile}

Fatty acid of the sample was determined by GC methods as described in AOAC (2002).

\subsubsection{Preparation of methyl ester of fatty acid}

Methyl ester weighed amount of oil $(1.0 \mathrm{~g})$ were transferred to a Teflon test tube. Methonolic potassium hydroxide $(0.5 \mathrm{~N} 10 \mathrm{ml})$ was then added to the oil sample. Mixture was relaxed until the globules of the oil got into solution 90 minutes. Sulphuric acid $(2 \mathrm{~N})$ was then added to the cooled mixture to liberate the fatty acids. Esterification of the liberated fatty acids was carried out in the presence of catalytic amount of methonal BF3 $(10 \mathrm{ml})$ and boil for 20 minutes. The etherified mixture was cooled and extracted with hexane. Separate hexane layers were washed with water and dried over anhydrous sodium sulfate.

\subsubsection{Determination of fatty acid methyl Easters}

The fatty acid composition of olive fruit pulp oils was determined by Gas Chromatography (Perkin elemyre 8410 series with flame ionization detector) using a column ( 2 meter) packed with celite coated with $10 \%$ DEGS. The GC operating conditions were: column temperature 140, FID temperature $270 \mathrm{C}$, injector temperature $260 \mathrm{C}$ and carrier gas nitrogen a flow rate of $40 \mathrm{ml} / \mathrm{min}$. The determined percentage fatty acid composition.

\subsection{Heavy meats}

\subsubsection{Sample preparation}

The way that is used in this study to digestion the olive oil sample is the digestion by nitric acid $\left(\mathrm{HNO}_{3}\right)$. A $0.5 \mathrm{~g}$ of olive oil sample is transferred into special tubes. A $2 \mathrm{ml}$ of NHO3 is transferred into the tube. The tubes were closed with stoppers, and the temperatures of the tubes increased from $75^{\circ} \mathrm{C}$ to $100^{\circ} \mathrm{C}$ gradually each hour. The final step was adding hydrogen peroxide $\left(\mathrm{H}_{2} \mathrm{O}_{2}\right)$ to the tubes. The temperatures of the tube increased from $75^{\circ} \mathrm{C}$ to $100^{\circ} \mathrm{C}$ gradually each hour. Finally the olive oil samples were ready to be inserted into ICP-MS device to determine the elemental concentration Lowther 1980.

Heavy metals were determined using Inductivity Coupled Argon Plasma iCAP 6500 Duo, Thermo Scientific, England. $1000 \mathrm{mg} / \mathrm{L}$ multi-element certified standard solution, Merck, Germany was used a stock solution for instrument standardization. 


\subsection{Statistical analysis}

Data obtained throughout this study were statistically analyzed using the analysis of variance method as reported by Snedecor and Cochran (1980) and the differences between means were differentiated by using Duncan's range test.

\section{Results and Discussion}

Adulteration of oils by adding cheap oils or with low grade and quality from the same type of oils is an old problem. The International Olive Council (IOC, 2013) and the European regulations (EC, 1991) have defined the olive oil quality, based on several parameters such as; free acidity content, peroxide value (PV), specific extinction coefficients (K232 and K270) and organoleptic evaluation. Refractive Index (RI), specific gravity (SG) acid value, free acidity \% (FFA), saponification value (SV) and peroxide value (PV) were presented in Table (2). Knowledge of the refractive index of oil is crucial importance in applications of identification and adulteration of oils and their purity (Yunus et al., 2009 and Rasha et al., 2017).The refractive index of oils depends on their molecular weight, fatty acid chain length, degree of unsaturation, and degree of conjugation. Values of refractive index for different oils generally vary between 1.4470 and 1.4820 (Shahidi, 2005). Virgin olive oil exhibited RI value with the international accepted limits of olive oil (1.4677-1.4705) (CODEX STAN 33-1981). Results showed that, the refractive index of olive oil obtained from mills in Matrouh Governorate ranged from 1.4598 to 1.4610. The differences in RI were slight significant and most of oils obtained from different mills fall within the accepted range and agreed with Shahidi, 2005. The same trend was found in specific gravity (SG) which was used as indicator for identity of the oils. The limits of Codex standards for virgin and refined olive oil was $0.909-0.915$. The results indicated that the specific gravity (SG) of olive oil samples for different mills ranged between 0.900- 0.960 (Table 2). All olive oil samples were statistically affected, yet their SG values were keeping within the accepted rang for extra virgin olive oils confirmed by the European Commission Regulation (EU, 2013), (IOC, 2016) and (ESS, 2016).

The Free acidity showed that mill No_2 which used the modern 2 phase method for extraction had the lowest value $(0.23 \%)$ among the different six mills under the present study. The highest value was recorded in mill No _ 1 which used the modern Simi pressing method for extraction $(0.80 \%)$ followed by Mill No _5 which used the modern Simi pressing method for extraction $(0.78 \%)$. The results showed that there are significant differences in the value of free acidity between different mills that may be due to the different pressing method. These increments may be due to the addition of exceeding water in modern Simi pressing and three-phases system more than in two-phases, likewise the oil from press system remains with the vegetable water together till separating by settling, which therefore can promote the triglycerides hydrolysis and release free fatty acids as mentioned by Torres and Maestri (2006). Free acidity values for all oils extracted with the three systems were compatible with IOC (2016) and (ESS, 2016); they were less than $0.8 \%$ as oleic acid for EVOO.

Table 2: Physical and chemical properties of olive oil samples obtained from different mills in Matrouh Governorate

\begin{tabular}{cccccc}
\hline & \multicolumn{2}{c}{ Physical properties } & \multicolumn{2}{c}{ Chemical properties } \\
\cline { 2 - 6 } Olive mills & $\begin{array}{c}\text { Refractive index } \\
\text { (RI) }\end{array}$ & $\begin{array}{c}\text { Specific gravity } \\
\text { (SG) }\end{array}$ & \% FFA & $\begin{array}{c}\text { Saponification } \\
\text { value }\end{array}$ & $\begin{array}{c}\text { Peroxide } \\
\text { value } \\
\text { meq.O } / \mathbf{O}^{2} \mathbf{k g}\end{array}$ \\
\hline Mill_1 & $1.4598 \pm 0.0003^{\mathrm{b}}$ & $0.931 \pm 0.0003^{\mathrm{c}}$ & $0.80 \pm 0.05^{\mathrm{a}}$ & $198 \pm 0.23^{\mathrm{b}}$ & $6.22 \pm 0.1$ \\
Mill_2 & $1.4600 \pm 0.0002^{\mathrm{b}}$ & $0.900 \pm 0.0009^{\mathrm{f}}$ & $0.23 \pm 0.03^{\mathrm{f}}$ & $195 \pm 0.09^{\mathrm{a}}$ & $7.98 \pm 0.2$ \\
Mill_3 & $1.4610 \pm 0.0002^{\mathrm{a}}$ & $0.941 \pm 0.0004^{\mathrm{b}}$ & $0.76 \pm 0.04^{\mathrm{c}}$ & $193 \pm 0.10^{\mathrm{e}}$ & $6.85 \pm 0.1$ \\
Mill_4 & $1.4610 \pm 0.0002^{\mathrm{a}}$ & $0.914 \pm 0.0008^{\mathrm{e}}$ & $0.57 \pm 0.03^{\mathrm{e}}$ & $182 \pm 011^{\mathrm{f}}$ & $9.44 \pm 0.1$ \\
Mill_5 & $1.4609 \pm 0.0003^{\mathrm{a}}$ & $0.923 \pm 0.0003^{\mathrm{d}}$ & $0.78 \pm 0.06^{\mathrm{b}}$ & $188 \pm 0.39^{\mathrm{c}}$ & $6.77 \pm 0.2$ \\
Mill_6 & $1.4600 \pm 0.0002^{\mathrm{b}}$ & $0.961 \pm 0.0004^{\mathrm{a}}$ & $0.77 \pm 0.05^{\mathrm{d}}$ & $182 \pm 0.13^{\mathrm{d}}$ & $6.35 \pm 0.3$ \\
EVOO IOC & $1.4677-1.4705^{*}$ & $0.910-0.915$ & $\leq 0.8$ & $184-196^{*}$ & $\leq 20$ \\
Standard 2016 & & & & &
\end{tabular}

Each value represents the mean \pm SD.

Mill_1= Modern (simi pressing); Mill_2= Modern (2 phase); Mill_3=Old (pressing); Mill_4 = Modern (3 phase); Mill_5=Modern (simi pressing); Mill_ $\_=$old (stone press) 
On the other hand, Peroxide value attained the highest value in mill $\mathrm{NO}_{-} 4\left(9.44\right.$ meq. $\left.\mathrm{O}_{2} / \mathrm{kg}\right)$ which used the modern ( 3 phase) method for extraction while, the lowest was in Mill No_1 (6.22 meq. $\mathrm{O}_{2} / \mathrm{kg}$ ) which used the modern Simi pressing method for extraction, data also indicate that the values of PV in mills which used three and two phase for extraction were significantly higher than those of oils extracted by the old and modern Simi pressing system. These findings may due to the no considerable amount of water which used into old and modern Simi pressing system compared to that in the three and two phase system. These observations are agreeing with that of Di Giovacchino et al (2002) and Abd El-Hamied et al., (2019).

\subsection{Fatty acid profile}

The fatty acid compositions of the different olive oils samples, total saturated fatty acids (SFA), polyunsaturated fatty acids (PUFA), monounsaturated fatty acids (MUFA), and MUFA/PUFA ratio are shown in Table (3). The results of fatty acid composition revealed that, palmitic acid (16:0) varies between (14.56-18.12\%) and the highest content of palmitic acid as saturated fatty acid was found in mill No 5 which used the modern simi pressing method for extraction. Meanwhile, oleic acid (18:1) varies between (61.61-74.13\%) and the highest content of oleic acid as unsaturated fatty acid (74.13\%) was found in mill No_2 which used the modern two phase method for extraction. while the lowest percent of oleic acid was found in mill No_5 which used the modern Simi pressing method for extraction.

Table 3: Fatty Acid Composition of olive oil samples obtained from different mills in Matrouh Governorate

\begin{tabular}{|c|c|c|c|c|c|c|c|}
\hline \multirow{2}{*}{ Test items } & \multicolumn{6}{|c|}{ Test results of fatty acids* } & \multirow[b]{2}{*}{ IOC Standard,2016 } \\
\hline & Mill_1 & Mill_2 & Mill_3 & Mill_4 & Mill_ 5 & Mill_6 & \\
\hline Sample code & 26 & 27 & 28 & 29 & 30 & 31 & \\
\hline C14:0 & 0.01 & 0.01 & 0.01 & 0.01 & 0.01 & 0.01 & $\leq 0.03$ \\
\hline C16:0 & 16.94 & 14.56 & 14.57 & 15.62 & 18.12 & 16.11 & $7.5-20.0$ \\
\hline C16:1 & 2.03 & 1.23 & 1.25 & 1.19 & 1.83 & 1.38 & $0.3-3.5$ \\
\hline C17:0 & 0.12 & 0.04 & 0.07 & 0.06 & 0.05 & 0.06 & $\leq 0.40$ \\
\hline C17:1 & 0.19 & 0.05 & 0.10 & 0.09 & 0.06 & 0.08 & $\leq 0.60$ \\
\hline C18:0 & 2.88 & 3.39 & 3.13 & 3.48 & 2.85 & 2.98 & $0.5-5.0$ \\
\hline C18:1 & 66.73 & 74.13 & 70.94 & 71.01 & 61.61 & 69.43 & $55.0-83.0$ \\
\hline C18:2T & 0.00 & 0.00 & 0.00 & 0.00 & 0.00 & 0.00 & $\mathrm{C} 18: 2 \mathrm{t}+\mathrm{C} 18: 3 \mathrm{t} \leq 0.05$ \\
\hline C18:2 & 9.64 & 5.18 & 8.19 & 7.15 & 14.00 & 8.51 & $2.5-21$ \\
\hline C18:3n6 & 0.02 & 0.01 & 0.02 & 0.02 & 0.01 & 0.01 & \\
\hline C18:3n3 & 0.65 & 0.58 & 0.74 & 0.57 & 0.70 & 0.70 & $\leq 1.0$ \\
\hline C20:0 & 0.43 & 0.45 & 0.43 & 0.45 & 0.42 & 0.40 & $\leq 0.60$ \\
\hline C20:1 & 0.23 & 0.23 & 0.24 & 0.21 & 0.19 & 0.22 & $\leq 0.5$ \\
\hline C22:0 & 0.11 & 0.11 & 0.10 & 0.11 & 0.11 & 0.07 & $\leq 0.20$ \\
\hline SFA & 20.49 & 18.56 & 18.31 & 19.73 & 21.56 & 19.63 & \\
\hline USFA & 79.49 & 81.41 & 81.48 & 80.24 & 78.4 & 80.33 & \\
\hline MUFA & 69.18 & 75.64 & 72.53 & 72.5 & 63.69 & 71.11 & \\
\hline PUFA & 10.31 & 5.77 & 8.95 & 7.74 & 14.71 & 9.22 & \\
\hline MUFA/PUFA & 6.71 & 13.11 & 8.10 & 9.37 & 4.33 & 7.71 & \\
\hline
\end{tabular}

*Test methods: ISO $12966-2(2011)$

Total saturated fatty acids (SFA), Total monounsaturated fatty acids (MUFA), Total poly- unsaturated fatty acids (PUFA)

Mill_1= Modern (simi pressing); Mill_2= Modern (2 phase); Mill_3= Old (pressing); Mill_4 = Modern (3 phase); Mill_5= Modern (simi pressing); Mill_ $6=$ old (stone press)(Guerfel et al., 2012).

The oleic acid is one of the importance unsaturated fatty acids, because of their nutritional implication and effect on oxidative stability of oil (Rasha et al., 2017). On the other hand, the highest linoleic acid was found in mill No_5 (14.0\%), linoleic acids (which is susceptible to oxidation) contents were the most useful and significant parameters for differentiating of mills which used different extraction method. In addition, linolenic acid contents were found less than $1 \%$ in all olive oil samples from 
different mills. The best composition of fatty acids was found in oil in mill No 3 which used the old pressing method for extraction, it contains the highest content of unsaturated fatty acids USFA $(81.48 \%)$ and the lowest content of saturated fatty acids SFA (18.31\%) as shown in Table (3).

The fatty acid composition of the olive oil in all mills was in the range of IOC trade standard (IOC, 2001, 2004, 2016).

Mladenka Šarolić et al., (2014) reported that the quality of virgin olive oil is related to it's contain a high percentage of monounsaturated fatty acids (mainly oleic acid). The oxidative stability and health properties of virgin olive oil come from a prominent and well-balanced chemical composition

The high percentage of oleic acid in olive oil working on slow down permeation of fatty acids into arterial walls (Mailer, 2006). Oil with higher monounsaturated fatty acids (MUFAs) and lower saturated fatty acids (SFAs) are preferred because of the proven beneficial effect of MUFAs on serum cholesterol levels (Hashempour et al., 2010).

Olive oil quality is related to the chemical composition of the oil, and its oxidative stability and sensory characteristics. These parameters are affected mainly by climatic conditions (Najaf et al., 2015 and Fares et al., 2016). Oleic acid values were significantly associated with mean temperature during oil accumulation (Rondanini et al., 2011 and Mabroka et al., 2014).

The MUSFA/PUSFA ratio is frequently used as a stability parameter and, in previous studies; the cultivar with higher ratios were those with higher oxidative stability (Beltran, 2000). Mill No _2 which used the modern method for extraction had the highest ratio from MUSFA/PUSFA (13.11) in accordance with their higher oxidative stability. While Mill No 5 which used the modern simi pressing for extraction had the lowest ratio 4.33 with considerable good oxidative stability (Table 3 ).

\subsection{Heavy metals}

Twenty elements were studied in six olive oil samples obtained from different mills. The concentrations of the metals in the samples are given in Tables 4. Variations in concentration of metals were observed between olive oil samples from different mills which used different extraction methods. These variations could be affected by soil, fertilizers, maturation and processing methods, or may be affected by weather and environmental conditions (rain, temperature, wind). The Mg levels have ranged from 0.1592 to $5.043 \mathrm{ppm}$, the lowest concentration was found in mill No_5 which used the Modern simi pressing methods for extraction while the highest concentration was in mill No_2 which used Modern two phase methods for extraction followed by mill No_6 (4.312 ppm) which used old stone method for extraction. Results indicate that concentrations of $\mathrm{Mg}$ may change according to processing methods and type and maturation of fruit olive. Concentrations of $\mathrm{Mg}$ in the olive oil sample were compared with other studies. In Zeiner's study the concentrations of $\mathrm{Mg}$ are ranged between 2.91-3.62 $\mu \mathrm{g} / \mathrm{g}$ (Zeiner et al., 2005). Nergiz and Engez reported that the range of $\mathrm{Mg}$ concentration in green olive is between $114-373 \mu \mathrm{g} / \mathrm{g}$.

The levels of iron $(\mathrm{Fe})$ in olive oil samples which vary between 0.8357 and $35.17 \mathrm{ppm}$, the lowest concentration from Iron was found in mill No_5 which used the modern simi pressing methods for extraction while the highest concentration was in mill No_2 which used modern two phase methods for extraction followed by mill No_6 (16.20 ppm) which used old stone method for extraction.

Data presented in table 4 shows that the levels of copper $(\mathrm{Cu})$ in olive oil samples vary between 0.0106 to $0.0511 \mathrm{ppm}$. The concentration of $\mathrm{Cu}$ is influenced by fertilizers and fungicides which are added to olive trees to fight fungal disease. Moreover a small concentration of $\mathrm{Cu}$ can act as a catalyst in the oxidation process so the $\mathrm{Cu}$ concentration should be controlled because it influences the olive oil quality (Sahan et al., 2007and Fuqha et al., 2015). On the other hand the levels of Al in olive oil samples from different mills ranged between 1.272 to $15.44 \mathrm{ppm}$, whereas the lowest concentration obtained from mill No_5 which used the modern simi pressing methods for extraction while mill no_2 which used modern two phase methods for extraction gave the highest concentration.

Concentration of elements may affect the quality of olive oil as storability, freshness or toxicity. The levels of $\mathrm{Cu}, \mathrm{Fe}$, and $\mathrm{Zn}$ cause an increase in the rate of oxidation. The levels of iron (Fe) in olive oil samples which vary between 0.8357 and $35.17 \mathrm{ppm}$. The values of Fe metal influenced by the Maturation, production condition and variety properties (Sahan et al., 2007 and Fuqha et al., 2015).

Table 4 shows the concentration of $(\mathrm{Ca})$ in the analyzed samples varied between 0.6634 and $17.71 \mathrm{ppm}$ this value is higher than other studies. According to $\mathrm{FAO} / \mathrm{WHO}$. 
Vegetable oils and fats contain trace levels of various metals depending upon many factors, such as species, soil used for the cultivation, irrigation water, variety, and stage of maturity. The main elements are $\mathrm{Ca}, \mathrm{Mg}, \mathrm{P}$, and $\mathrm{Fe}$ followed by ultra-trace level of $\mathrm{Zn}, \mathrm{Cr}, \mathrm{Mn}, \mathrm{Ni}$, and $\mathrm{Cu}$ (Ansari et al., 2008).

The contaminated by the heavy metals in olive oil may be occurring during the production process and contact with stored materials. The level of heavy metals in olive oils is one of the quality parameters and also effective on oil oxidation and human health. Cadmium is known as a highly toxic trace metal and excessive consumption of it may give rise to human diseases such as renal, pulmonary, hepatic, and skeletal and cancer (Zhu, et al., 2011).

Table 4: The Concentration of Heavy Metals (ppm) of of olive oil samples obtained from different mills in Matrouh Governorate

\begin{tabular}{|c|c|c|c|c|c|c|}
\hline Elem. & Mill_1 & Mill_2 & Mill_3 & Mill_4 & Mill_5 & Mill_6 \\
\hline Al & 3.992 & 15.44 & 4.855 & 1.680 & 1.272 & 4.401 \\
\hline As & ND & ND & ND & ND & ND & ND \\
\hline B & $<0.0004$ & $<0.0004$ & $<0.0004$ & $<0.0004$ & $<0.0004$ & $<0.0004$ \\
\hline Ba & 0.0389 & 0.0422 & $<0.004$ & $<0.004$ & $<0.004$ & 0.0460 \\
\hline $\mathbf{B i}$ & $<0.002$ & $<0.002$ & $<0.002$ & $<0.002$ & $<0.002$ & $<0.002$ \\
\hline $\mathrm{Ca}$ & 11.13 & 17.71 & 1.276 & 0.8282 & 0.6634 & 16.73 \\
\hline Cd & 0.0100 & $<0.0006$ & $<0.0006$ & $<0.0006$ & 0.0129 & 0.0032 \\
\hline Co & $<0.001$ & $<0.001$ & $<0.001$ & $<0.001$ & $<0.001$ & $<0.001$ \\
\hline $\mathrm{Cr}$ & 0.1651 & 0.2199 & 0.0204 & $<0.01$ & $<0.01$ & 0.2157 \\
\hline $\mathrm{Cu}$ & 0.0366 & 0.0444 & 0.0171 & 0.0106 & 0.0191 & 0.0511 \\
\hline $\mathbf{F e}$ & 13.05 & 35.17 & 1.900 & 0.9917 & 0.8357 & 16.20 \\
\hline $\mathrm{Hg}$ & ND & ND & ND & ND & ND & ND \\
\hline Mg & 2.218 & 5.043 & 0.3360 & 0.1707 & 0.1592 & 4.312 \\
\hline Mn & 0.1201 & 0.8756 & 0.0390 & 0.0157 & 0.0188 & 0.3284 \\
\hline Mo & $<0.001$ & 0.0280 & 0.0664 & 0.0508 & $<0.001$ & $<0.001$ \\
\hline $\mathrm{Ni}$ & 0.1851 & 0.1725 & 0.0368 & 0.1020 & 0.0604 & 0.1389 \\
\hline $\mathbf{P}$ & ND & ND & ND & ND & ND & ND \\
\hline $\mathbf{P b}$ & ND & ND & ND & ND & ND & ND \\
\hline Sb & $<0.008$ & $<0.008$ & $<0.008$ & 0.0217 & 0.0334 & 0.0334 \\
\hline Se & ND & ND & ND & ND & ND & ND \\
\hline Sn & 12.47 & 16.88 & 1.125 & 0.5672 & 0.5397 & 13.28 \\
\hline $\mathrm{Sr}$ & ND & ND & ND & ND & ND & ND \\
\hline $\mathbf{T i}$ & 0.0567 & 0.1024 & 0.0065 & 0.0040 & 0.0031 & 0.0857 \\
\hline Tl & ND & ND & ND & ND & ND & ND \\
\hline V & 0.6849 & 0.9032 & 1.263 & 0.6740 & 0.3848 & 0.0956 \\
\hline Zn & $<0.01$ & 0.0148 & $<0.01$ & $<0.01$ & 0.0074 & 0.0192 \\
\hline Ag & 0.1362 & 0.4443 & $<0.0006$ & $<0.0006$ & 0.0010 & 0.3151 \\
\hline
\end{tabular}

Mill_1= Modern (simi pressing); Mill_2= Modern (2 phase); Mill_3=Old (pressing); Mill_4 = Modern(3 phase); Mill_5= Modern (simi pressing); Mill_6= old (stone press)

\section{Conclusion}

There were no significant differences among olive oil mills and extraction techniques which used in these mills in view of Physicochemical Analysis. On the other hand, there were slight differences in free fatty acids $\%$ and fatty acids composition between different olive oil mills. Fatty acid profiles for all olive oil samples were in the range of virgin olive oil according to IOC Standard and all mills were identical with permitted limits of extra virgin olive oil. On the overall, Olive oil mill No_2 showed that higher concentration of heavy metal than other mills under study. We found that the content of the heavy metals in all of the tested oils was lower than the maximum values recommended for FAO/WHO.

\section{Acknowledgement}

The authors thank the Faculty of Home Economics, Menoufiya University, Desert Research Center and National Research Centre, Egypt for funding and supporting this work. 


\section{Conflict of interest}

The authors declare that there are no conflicts of interest.

\section{References}

A.O.A.C. 2000. Official Methods of Analysis 17th Edition, Association of Official Agric. Chem. Washington D.C. 1970.

Abd El-Hamied W.A., A.Y. Girgis and Magda H. Allam, 2019. Effect Of Extraction Systems On Quality Characteristics Of Extra Virgin Olive Oil Arab Univ. J. Agric. Sci., Ain Shams Univ., Cairo, Egypt 27(4): 2167-2176.

Alimentarius, C., 1999. Codex standard for named vegetable oils. Codex Stan., 210: 1-13.

Anonymous 2. Commission implementing regulation (EU) No 299/2013 of 26 March 2013 amending Regulation (EEC) No 2568/91 on the characteristics of olive. https://eur-lex. europa. eu/ Lex Uri Serv/LexUriServ.do?uri=OJ:L:2013:090:0052:0070:EN:PDF

Ansari R., T.G. Kazi, M.K. Jamali, M.B. Arain, S.T. Sherazi, N. Jalbani, and H.I. Afridi, 2008. Improved extraction method for the determination of iron, copper and nickel in new varieties of sunflower oil by atomic absorption spectroscopy, J. AOAC Int. 91: 400-407.

Azbar, N., A. Bayram, I.A. Filibel, A. Muezzinoglu, F. Sengul, and A. Ozer, 2004. A review of waste management options in olive oil production. Crit. Rev. Environ. Sci. Technol., 34: 209-47.

Beltran, G., 2000. Influence of Ripening Process in Olea europaea L. Fruits on the Physicochemical Characteristics of the Oils. Ph.D. Thesis, Universidad de Jaen, Spain

Benedet, J.A. and Shibamoto T. 2008. Role of Transition Metals, $\mathrm{Fe}(\mathrm{II}), \mathrm{Cr}(\mathrm{II}), \mathrm{Pb}(\mathrm{II})$, and $\mathrm{Cd}(\mathrm{II})$ in Lipid Peroxidation. Food Chemistry, 107: 165-168, ISSN 0308-8146.

Codex Standard for Olive Oil, Virgin and Refined, and For Refined Olive-Pomace Oil Codex Stan 331981 (Rev. 1-1989)

Di Giovacchino L., L.S. Sestili and D. Di Vincenzo 2002. Influence of Olive Processing on Virgin Olive Oil Quality. Eur. J. Lipid Sci. Tech-nol., 104: 587-601.

EEC, 1991. Characteristics of olive and olive pomace oils and their analytical methods. Regulation EEC / 2568 / 91 and latter modifications. Official Journal of the European Communities, L, 248: 1 82.

Egyptian Standards Specifications, 2016. Vegetable edible oils, part: 2; olive oils and olive pomace oils. ES: 49- 2, Egyptian Organization for Standardization and Quality, Egypt.

European Commission (EC), 2001. Council Regulation (EC) No. 1513/2001 of 23 July 2001 amending regulation (EC) 136/66/EEC and No. 1638/98 as regards the extension of the period of validity of the aid scheme and the quality strategy for olive oil. Off. J. Commun. L 201, 407. http://www.internationaloliveoil.org/estaticos/view/132-worldtable-olive-figures

European Union, 2013. Commission Implementing Regulation (EU) No 299/2013 of 26 March, Official Journal of the European Union

European Union Commission Regulations, 1991. Commission Regulation, 2568/91 on the characteristics of olive oil and olive residue oil and on the relevant methods of analysis. Official J. of the European Communities, July 11(248): 1-83.

FAO/WHO, 1976. Standards, list of maximum levels recommended for contaminants by the joint,

Fares, N., I. Karoui Jabri, S. Sifi and M. Abderrabba, 2016. Physical chemical and sensory characterization of olive oil of the region of Kairouan . J. Mater. Environ. Sci., 7(6): 2148-2154.

Fuqha, E., M. Abu-Jafar, and I.R. Iabdelraziq, 2015. Determination of Some Metallic Elements and their Effect on Physical Properties of Edible Olive Oil in Palestine. J. Material. Sci. Eng 5: 210. doi:10.4172/2169-0022.1000210.

Guerfel, M., M.B. Mansour, Y. Ouni, D. Boujnah and M. Zarrouk, 2012. Compositional quality of virgin olive oils from cultivars introduced in two Tunisian locations. African Journal of Agricultural Research, 7(16): 2469-2474.

Hashempour, A., R.F. Ghazvini, D. Bakhshi and S.A. Sanam, 2010. Fatty acids composition and pigments changing of virgin olive oil (Olea europea L.) in five cultivars grown in Iran. AJCS 4(4): 258-263 ISSN: 1835-2707. 
International Olive Council (IOC), 2013. Trade Standard Applying to Olive Oils and Olive-Pomace Oils. T.15/NC No 3/Rev.7.

International Olive Council, 2016. http://www. internationaloliveoil.org

IOC, 2012. Olive Oil Production, Consumption, Export. International Olive Oil Council, Madrid, Available Online.

IOOC (International Olive Oil Council), 2001. Preparation of the fatty acid methyl esters from olive oil and olive-pomace oil. International Olive Oil Council, Madrid.

IOOC, Olive oil exportations. International Olive Oil Council, 2004, http://www. International olive oil .org.

Khaniki, G., 2007. Chemical contaminants in milk and public health concerns: a review. Int. J. Dairy Sci., 2(2): 104-15.

Lowther J.R., 1980. Use of a single sulphuric acid and hydrogen peroxide digest for the analysis of pinus radiata needles, Communications in Soil Science and Plant Analysis, 11:2, 175-188, DOI: $10.1080 / 00103628009367026$.

Mabroka, H., Hemida, Amal A.E. Ibrahim, Rasha M. Al-Bahnsawy and Mona R. Al-Shathly, 2014. Influence of Environmental factors on Olive Oil Production and Quality in the Northern Region of Kingdom of Saudi Arabia. Journal of American Science, 10(1): 61-66.

Meira, M., C.M. Quintella, A.S. Tanajura, H.R.G. da Silva, J. D’Erasmo Santos Fernando, P.R.C. Netoc, I.M. Pepe, M.A. Santos, and L.L. Nascimento, 2011. Determination of the Oxidation Stability of Biodiesel and Oils by Spectrofluorimetry and Multivariate Calibration. Talanta, 85, 430-434.http://dx.doi.org/10.1016/j.talanta.2011.04.002

Mladenka Š., G. Mirko, M. Zvonimir and Š. Marko, 2014. Virgin olive oil and nutrition. Food in health and disease, scientific-professional journal of nutrition and dietetics (2014) 3 (1) 38-43.

Najafi1, V., M. Barzegar and M.A. Sahari, 2015. Physicochemical Properties and Oxidative Stability of Some Virgin and Processed Olive Oils. J. Agr. Sci. Tech., 17: 847-858.

Nergiz, C., and Y. Engez, 2000. Compositional variation of olive fruit during ripening. Food Chemistry, 69: 55-59.

Oreopoulou, V. and W. Russ, 2007. Utilization of by-products and treatment of waste in the food industry. Iseki-food series. Springer.

Rasha M.E.B., Naglaa H.M. Hassanen and M.E. Mounir, 2017. Comparative Study of the Quality of Extra Virgin Olive Oil in the Egyptian Market (from different Mediterranean countries). Curr. Sci. Int., 6(1): 208-217.

Rondanini, D.P., D.N. Castro, P.S. Searles and M.C. Rousseaux, 2011. Fatty acid profiles of varietal virgin olive oils (Olea europaea L.) from mature orchards in warm arid valleys of Northwestern Argentina (La Rioja). Grasas Y Aceites, 62(4), octubre-diciembre, 399-409.

Sahan, Y., F. Basoglu, and S. Gucer, 2007. ICP-MS analysis of a series of metals (Namely: Mg, Cr, Co, $\mathrm{Ni}, \mathrm{Fe}, \mathrm{Cu}, \mathrm{Zn}, \mathrm{Sn}, \mathrm{Cd}$ and $\mathrm{Pb}$ ) in black and green olive samples from Bursa, Turkey. Food Chemistry, 105: 395-399.

Shahidi, F., 2005. Quality Assurance of Fats and Oils In Bailey's Industrial Oil and Fat Products, Sixth Edition, Six Volume Set. Edited by Fereidoon Shahidi. Copyright (C) 2005 John Wiley and Sons, Inc.

Sikwese, F.E. and K.G. Duodu, 2007. Antioxidant Effect of A Crude Phenolic Extract from Sorghum Bran in Sunflower Oil in the Presence of Ferric Ions. Food Chemistry, 104: 324-331, ISSN 0308-8146.

Snedecor, G.W. and W.G. Cochran, 1980. Statistical methods.7th Ed., p. 420. Iowa Stat. Univ. Press, Ames, Iowa, USA.

Standard for Olive Oils and Olive Pomace Oils Codex Stan 33-1981 Adopted in 1981. Revision: 1989, 2003, 2015. Amendment: 2009, 2013.

Torres M.M. and D.M. Maestri, 2006. The effects of genotype and extraction methods on chemi-cal composition of virgin olive Oils from Traslasierra Valley (Córdoba, Argentina). Food Chemistry, 96: 507-511.

Tsagaraki, E., H.N. Lazarides, and K.B. Petrotos, 2004. Olive mill wastewater treatment. Util ByProducts Treat Waste Food Ind., 133-57. 
Yunus, W.M.M., Y.W. Fen, and L.M. Yee, 2009. Refractive Index and Fourier Transform Infrared Spectra of Vigin Coconut oil and Virgin Olive Oil. American Journal of Applied Sciences, 6 (2): 328-331.

Zeiner, M., I. Steffan, and I.J. Cindric 2005. Determination of trace elements in olive oil by ICP-AES and ETA-AAS: A pilot study on the geographical characterization. Microchemical Journal, 81: 171-176.

Zhu, F., W. Fan, X. Wang, L. Qu, and S. Yao, 2011. Health risk assessment of eight heavy metals in nine varieties of edible vegetable oils consumed in China, Food and Chemical Toxicology, 49: 3081-3085. 